\title{
Characteristics of 2017 GOLD COPD group A: a multicenter cross-sectional CAP study in Japan
}

This article was published in the following Dove Press journal: International Journal of COPD

\author{
Keiji Oishi' \\ Tsunahiko Hirano \\ Kazuki Hamada ${ }^{2}$ \\ Sho Uehara ${ }^{2}$ \\ Ryo Suetake ${ }^{2}$ \\ Yoshikazu Yamaji ${ }^{2}$ \\ Kosuke Ito² \\ Maki Asami-Noyama ${ }^{2}$ \\ Nobutaka Edakuni ${ }^{2}$ \\ Kazuto Matsunaga ${ }^{2}$ \\ 'Department of Medicine and \\ Clinical Science, Graduate School of \\ Medicine, Yamaguchi University, Ube, \\ Yamaguchi, Japan; ${ }^{2}$ Department of \\ Respiratory Medicine and Infectious \\ Disease, Graduate School of \\ Medicine, Yamaguchi University, Ube, \\ Yamaguchi, Japan
}

Purpose: The 2017 GOLD ABCD classification shifts patients from groups C-D to A-B. Group A was the most widely distributed group in several studies. It would be useful to understand the characteristics for group A patients, but little has been reported concerning these issues.

Patients and methods: This was a multicenter cross-sectional study using the COPD Assessment in Practice study database from 15 primary or secondary care facilities in Japan. We investigated the clinical characteristics of group A by stratification according to a mMRC grade 0 or 1 .

Results: In 1,168 COPD patients, group A patients accounted for approximately half of the patients. Compared with the groups B-D, group A was younger and had a higher proportion of males, higher pulmonary function, and higher proportion of monotherapy with long-acting muscarinic antagonist or long-acting $\beta$-agonist. The prevalence of mMRC grade 1 patients was about two-thirds of group A. Compared with the mMRC 0 patients, mMRC 1 patients showed a tendency to have a higher proportion of exacerbations $(P=0.054)$ and had a significantly lower pulmonary function. Regardless of the mMRC grade, $60 \%$ of group A patients were treated with monotherapy of long-acting muscarinic antagonist or long-acting $\beta$-agonist.

Conclusion: Group A patients accounted for approximately half of the patients, and they were younger, had higher pulmonary function, and had lower pharmacotherapy intensity compared with groups B-D. By stratifying according to the mMRC grade 0 or 1 in group A patients, there were differences in the exacerbation risk and airflow limitation.

Keywords: COPD, GOLD, mMRC, exacerbation

\section{Introduction}

COPD, attracting attention for its high prevalence and mortality worldwide, is characterized by persistent airflow limitation that is usually progressive. ${ }^{1}$ The prevalence of COPD in Japan is reported to be $8.6 \%,{ }^{2}$ which is comparable with the global prevalence. ${ }^{3}$ There have been recent updates to the GOLD guideline, which is the most widely used treatment guide. ${ }^{4}$ One important change is the ABCD assessment tool, which has been modified to utilize only respiratory symptoms and history of exacerbations. The revised schema includes the following: group A, patients with few symptoms and no exacerbations; group B, patients with more symptoms but low risk of exacerbations; group $\mathrm{C}$, patients with exacerbations but few symptoms; and group D, patients with symptoms and risk of exacerbation.

Very recently, a few studies have reported comparisons of the 2017 and 2015 GOLD ABCD classification. Compared with the 2015 schema, the 2017 GOLD ABCD classification significantly shifts patients from groups $\mathrm{C}$ and $\mathrm{D}$ to groups $\mathrm{A}$ and $\mathrm{B} .{ }^{5,6}$ Notably, group A is the most widely distributed group in these studies. Although it 
would be useful to understand the characteristics, outcome, and pharmacotherapy for group A patients, few details have been reported. Therefore, we herein investigated the clinical characteristics of group A using the COPD Assessment in Practice (CAP) study database, ${ }^{7}$ and group A patients were stratified according to the $\mathrm{mMRC}$ scale (grade 0 or 1 ).

\section{Patients and methods Subjects}

Patients with COPD were enrolled from three primary care facilities and 12 secondary care facilities in Japan from April 2013 to May 2014. COPD was diagnosed as postbronchodilator $\mathrm{FEV}_{1} / \mathrm{FVC}$ of $<0.7$. Patients with other pulmonary diseases, such as asthma and bronchiectasis, or with disorders that would prevent them from being able to complete the study assessments, were excluded. Patients were excluded if they had experienced exacerbations during the 4 weeks prior to the study. Medical information and patients' characteristics including age, smoking status, the severity of disease, and current medication information were obtained from the patients' medical charts.

\section{Protocol}

This was a multicenter, cross-sectional study registered with the University Hospital Medical Information Network (UMIN \#000012592) and approved by the ethics committee of Wakayama Medical University (approval date: May 7, 2014; approval \#: 1410). This study was conducted in accordance with the Declaration of Helsinki. Written informed consent was obtained from all study participants.

\section{Assessment of physiological properties}

The procedures of the pulmonary function tests were in compliance with the American Thoracic Society (ATS)/ European Respiratory Society (ERS) guidelines. ${ }^{8}$ Postbronchodilator $\mathrm{FVC}$ and $\mathrm{FEV}_{1}$ were measured using a dry rolling seal spirometer on the same day. The spirometric reference values used have been reported by the Japanese Respiratory Society for $\mathrm{FEV}_{1} \cdot{ }^{9}$ The severity rankings of COPD, such as GOLD I-IV, were based on $\% \mathrm{FEV}_{1}$ according to the GOLD guidelines. ${ }^{4}$ Dyspnea was evaluated with the mMRC scale, which comprises five statements that describe the extent of respiratory disability from no disability (grade 0 ) to almost complete incapacity (grade 4$).^{10}$

\section{Assessment of exacerbation}

An exacerbation was defined as an acute event characterized by a worsening of respiratory symptoms that was beyond normal day-to-day variations and led to a change in medication. ${ }^{11}$ The requirement for systemic corticosteroids or antibiotics and the number of hospitalizations due to COPD during the previous 1 year were determined by review of the medical records, ${ }^{12}$ and these data were confirmed by a patient interview.

\section{Statistical analysis}

The data were expressed as the mean \pm standard deviation or median and interquartile range. The data were subjected to the normality test using the Shapiro-Wilk test prior to all statistical tests. The clinical characteristics of group A and groups $\mathrm{B}-\mathrm{D}$ were compared using $t$-tests and chi-squared tests. The clinical characteristics of mMRC grade 0 and mMRC grade 1 in group A and groups B-D were compared using Kruskal-Wallis and Mann-Whitney $U$ and chi-squared tests. $P<0.05$ was considered statistically significant. All statistical analyses were performed with EZR (Saitama Medical Center, Jichi Medical University, Saitama, Japan; http:// www.jichi.ac.jp/saitama-sct/SaitamaHP.files/statmedEN.

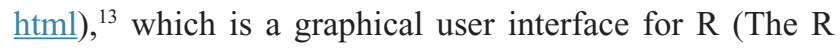
Foundation for Statistical Computing, Vienna, Austria, version 2.13.0). ${ }^{13}$

\section{Results}

A total of 1,168 patients, aged 40-95 years, were recruited and analyzed for the study. We classified patients by the 2015 and 2017 GOLD ABCD classification, and the proportion and the change within each group are shown in Figure 1.

For 2017, a treemap displays the proportion of 2017 GOLD ABCD classification including the stratified group A according to the mMRC grade and exacerbation history. The new classification significantly increased the proportion of patients in groups $\mathrm{A}$ and $\mathrm{B}$, while it decreased the proportion of patients in groups $C$ and D. According to the 2017 GOLD ABCD classification, about half of the patients were group A (569 patients, 49\%). There were $15.3 \%$ patients with mMRC grade 0 and no exacerbation history, 3.0\% patients with mMRC grade 0 and a history of one exacerbation, $23.4 \%$ patients with mMRC grade 1 and no exacerbation history, and $7.0 \%$ patients with mMRC grade 1 and a history of one exacerbation.

The clinical characteristics of group A and groups B-D are shown in Table 1. Patients in group A were younger than those in groups $\mathrm{B}-\mathrm{D}(P<0.0001)$. The proportion of males was higher in group $\mathrm{A}$ than in the groups $\mathrm{B}-\mathrm{D}(P<0.01)$. There were more current smokers in the group $A$ than in groups $\mathrm{B}-\mathrm{D}(P<0.005)$. There were significant differences in $\mathrm{FVC}, \mathrm{FEV}_{1}, \mathrm{FEV}_{1} / \mathrm{FVC}$, and $\% \mathrm{FEV}_{1}$ between group $\mathrm{A}$ and groups $\mathrm{B}-\mathrm{D}$. The proportion of monotherapy of long-acting 


\section{GOLD}

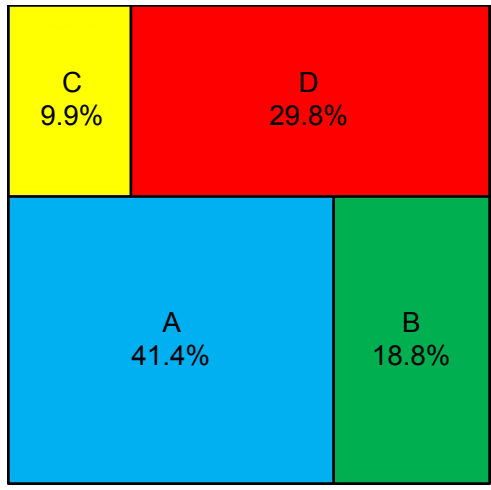

\section{GOLD}

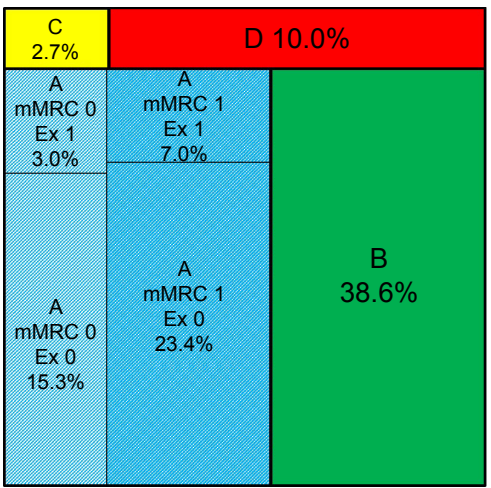

Group A, n=569 (48.7\%)

mMRC 0, Ex 0, $n=179(15.3 \%)$

mMRC 0, Ex 1, n=35 (3.0\%)

[mMRC 1, Ex 0, $n=273(23.4 \%)$

mMRC 1, Ex 1, n=82 (7.0\%)

Group B, $n=451$ (38.6\%)

Group C, $n=31(2.7 \%)$

Group D, n=117 (10.0\%)

Figure I Distribution of the 2015 GOLD and 2017 GOLD ABCD classification when stratifying group A according to the mMRC grade and exacerbation history. Note: The 2017 GOLD classification significantly increased the proportion of patients in groups $A$ and $B$, while it decreased the proportion of patients in groups C and D. Abbreviation: Ex, exacerbation.

muscarinic antagonist (LAMA) or long-acting $\beta$-agonist (LABA) was higher in group A than in groups B-D $(58.5 \%$ vs $35.4 \%, P<0.0001)$. In contrast, the proportion of combination therapy of LAMA and LABA was lower in group A than in groups $\mathrm{B}-\mathrm{D}(34.1 \%$ vs $62.6 \%, P<0.0001)$.

The proportion of group A as the severity of airflow limitation is shown in Figure 2. The more severe the airflow limitation was, the lower the proportion of group A.
The differences in the clinical characteristics between mMRC grades 0 and 1 in group A are shown in Table 2. The difference in exacerbations between mMRC grades 0 and 1 in group A patients was not statistically significant $(P=0.054)$ but demonstrated a trend toward more exacerbations in the mMRC grade 1 group. There were significant differences in $\mathrm{FVC}, \mathrm{FEV}_{1}, \mathrm{FEV}_{1} / \mathrm{FVC}$, and $\% \mathrm{FEV}_{1}$ between $\mathrm{mMRC}$ grades 0 and 1 . There was no significant difference in the

Table I Patient characteristics between group A and groups B-D

\begin{tabular}{|c|c|c|c|}
\hline Characteristics & $\begin{array}{l}\text { Group A } \\
(n=569)\end{array}$ & $\begin{array}{l}\text { Groups B-D } \\
(n=599)\end{array}$ & $P$-value \\
\hline Age, years & $70.6 \pm 8.3$ & $73.5 \pm 8.1$ & $<0.000 \mathrm{I}$ \\
\hline Male & $519(91.2)$ & $516(86.1)$ & $<0.01$ \\
\hline Never smoker & $24(4.2)$ & $25(4.2)$ & 0.77 \\
\hline Former smoker & $456(80.2)$ & $518(86.5)$ & $<0.01$ \\
\hline Current smoker & $89(15.6)$ & $56(9.3)$ & $<0.01$ \\
\hline mMRC, grade & $0.62 \pm 0.48$ & $2.44 \pm 0.75$ & $<0.000$ I \\
\hline FVC, L & $3.22 \pm 0.79$ & $2.6 I \pm 0.77$ & $<0.0001$ \\
\hline $\mathrm{FEV}_{1}, \mathrm{~L}$ & $1.83 \pm 0.60$ & $|.27 \pm 0.5|$ & $<0.0001$ \\
\hline $\mathrm{FEV}_{1} / \mathrm{FVC}, \%$ & $56.4 \pm 10.7$ & $48.6 \pm 12.1$ & $<0.0001$ \\
\hline $\mathrm{FEV}, \%$ of predicted, $\%$ & $69.9 \pm 18.3$ & $50.1 \pm 17.7$ & $<0.0001$ \\
\hline GOLD I & $176(30.9)$ & $35(5.8)$ & $<0.0001$ \\
\hline GOLD 2 & $308(54.1)$ & $255(42.6)$ & $<0.0001$ \\
\hline GOLD 3 & $75(13.2)$ & $229(38.2)$ & $<0.0001$ \\
\hline GOLD 4 & $10(1.8)$ & $80(13.4)$ & $<0.0001$ \\
\hline Exacerbation, year-1 & $0.21 \pm 0.40$ & $0.83 \pm 1.06$ & $<0.0001$ \\
\hline Long-term oxygen therapy & $12(2.1)$ & III (19.5) & $<0.0001$ \\
\hline Any COPD medication & $536(94.2)$ & $590(98.5)$ & $<0.0001$ \\
\hline Any LAMA or LABA medication & $527(92.6)$ & $587(98.0)$ & $<0.0001$ \\
\hline Monotherapy of LAMA or LABA & $333(58.5)$ & $212(35.4)$ & $<0.0001$ \\
\hline LAMA or LABA, non-use of ICS & $228(40.1)$ & $133(22.2)$ & $<0.0001$ \\
\hline LAMA or LABA, + ICS & $105(18.5)$ & $79(13.2)$ & $<0.05$ \\
\hline Combination therapy of LAMA + LABA & $194(34.1)$ & $375(62.6)$ & $<0.0001$ \\
\hline LAMA + LABA, non-use of ICS & $92(16.2)$ & $155(25.9)$ & $<0.0001$ \\
\hline LAMA + LABA, + ICS & $102(17.9)$ & $220(36.7)$ & $<0.0001$ \\
\hline
\end{tabular}

Note: Data are presented as $n(\%)$, mean $\pm S D$, or median (interquartile range).

Abbreviations: ICS, inhaled corticosteroid; LABA, long-acting $\beta$-agonist; LAMA, long-acting muscarinic antagonist. 
CAP study GOLD 1, $\mathrm{n}=211(18 \%)$

( $n=1,168) \quad$ GOLD 2, $n=563(48 \%)$

GOLD 3, n=304 (26\%)

(\%) GOLD $4, n=90(8 \%)$
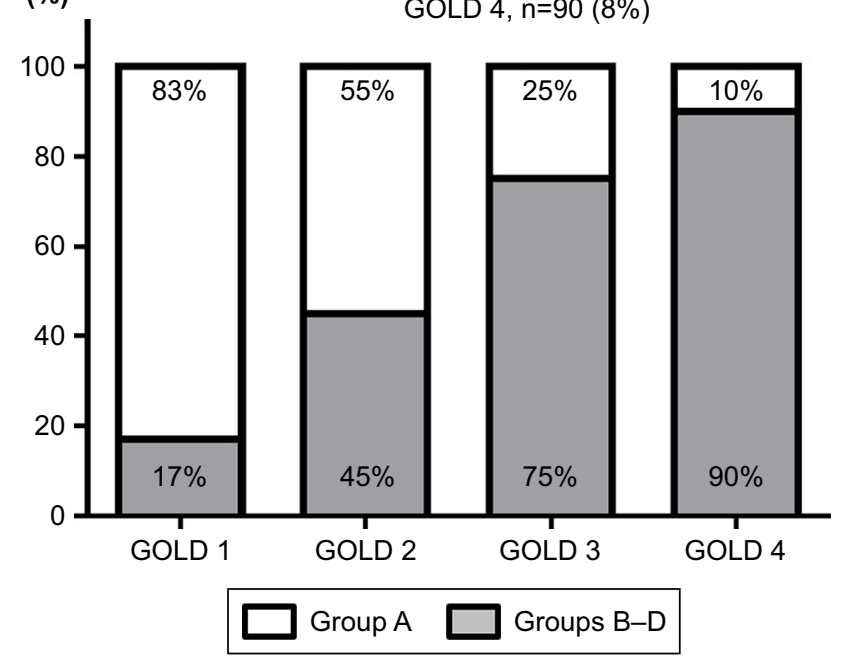

Figure 2 The proportion of group A according to the severity of airflow limitation. Note: The more severe the airflow limitation was, the lower the proportion of group A.

Abbreviation: CAP, COPD Assessment in Practice.

proportion of monotherapy of LAMA or LABA between the mMRC grades 0 and $1(60.7 \%$ vs $57.2 \%, P=0.66)$.

Significant differences in $\% \mathrm{FEV}_{1}$ were found between the categories of mMRC grade 0 in group $A$ and mMRC grade 1 in group A, group A, and groups B-D (Figure 3A).
Regarding the proportion of patients with exacerbations, a significant difference between group A and groups B-D was found, and a difference between mMRC grades 0 and 1 in group A was found (Figure 3B).

\section{Discussion}

Our study revealed two important clinical issues. Under 2017 GOLD, group A patients in Japan with COPD accounted for approximately half of the patients, and they were younger, had higher pulmonary function, and had lower pharmacotherapy intensity compared with groups B-D. The prevalence of mMRC grade 1 patients was about two-thirds of the group $\mathrm{A}$ and, compared with the mMRC 0 patients, mMRC 1 patients had a tendency to have a higher proportion of exacerbations and had a significantly lower pulmonary function and, regardless of the mMRC grade, there was not much difference in physicians' pharmacotherapy selection in group A.

First, group A patients with COPD accounted for approximately half of the patients, and they were younger, had higher pulmonary function, and had lighter pharmacotherapy intensity compared with groups B-D. Based on the ABCD classification in 2015 GOLD, this was consistent with the severity of airflow limitation ( $\left.\% \mathrm{FEV}_{1}\right)$, severity of symptoms (COPD Assessment Test [CAT] and mMRC scale), and history of exacerbations. The ABCD classification in the 2017 GOLD has been modified to utilize only the severity

Table 2 Patient characteristics between $m M R C$ grades 0 and $I$ in group $A$

\begin{tabular}{|c|c|c|c|}
\hline Characteristics & $\begin{array}{l}\mathrm{mMRC} 0 \\
(\mathrm{n}=2 \mid 4)\end{array}$ & $\begin{array}{l}\text { mMRC I } \\
(n=355)\end{array}$ & $P$-value \\
\hline Age, years & $71(66-77)$ & $71(66-77)$ & 0.43 \\
\hline Male & $195(91.1)$ & $324(91.3)$ & 0.95 \\
\hline Never smoker & $7(3.3)$ & $17(4.8)$ & 0.38 \\
\hline Former smoker & $172(80.3)$ & $286(80.6)$ & 0.96 \\
\hline Current smoker & $35(16.4)$ & $52(14.6)$ & 0.58 \\
\hline FVC, L & $3.34(2.78-3.96)$ & $3.18(2.67-3.56)$ & $<0.01$ \\
\hline $\mathrm{FEV}_{1}, \mathrm{~L}$ & $2.01(1.59-2.50)$ & $1.73(1.32-2.10)$ & $<0.0001$ \\
\hline $\mathrm{FEV}_{1} / \mathrm{FVC}, \%$ & $60.9(53.9-66.7)$ & $56.3(47.1-64.4)$ & $<0.0001$ \\
\hline $\mathrm{FEV}, \%$ of predicted, $\%$ & $77.7(62.1-88.3)$ & $67.7(55.5-79.0)$ & $<0.0001$ \\
\hline GOLD I & $94(43.9)$ & $82(23.1)$ & $<0.0001$ \\
\hline GOLD 2 & $97(45.3)$ & $211(59.4)$ & $<0.01$ \\
\hline GOLD 3 & $23(10.7)$ & $52(14.6)$ & 0.18 \\
\hline GOLD 4 & $0(0.0)$ & $10(2.8)$ & $<0.05$ \\
\hline Exacerbation & $35(16.4)$ & $82(23.1)$ & 0.054 \\
\hline Long-term oxygen therapy & $5(2.3)$ & $7(2.0)$ & 0.77 \\
\hline Any COPD medication & $197(92.1)$ & $339(95.5)$ & 0.09 \\
\hline Any LAMA or LABA medication & $188(87.9)$ & $339(95.5)$ & $<0.001$ \\
\hline Monotherapy of LAMA or LABA & $130(60.7)$ & $203(57.2)$ & 0.66 \\
\hline LAMA or LABA, non-use of ICS & $87(40.7)$ & 141 (39.7) & 0.83 \\
\hline LAMA or LABA, + ICS & $43(20.1)$ & $62(17.5)$ & 0.43 \\
\hline Combination therapy of LAMA + LABA & $58(27.1)$ & $136(38.3)$ & $<0.01$ \\
\hline LAMA + LABA, non-use of ICS & $22(10.3)$ & $70(19.7)$ & $<0.01$ \\
\hline LAMA + LABA, + ICS & $36(16.8)$ & $66(18.6)$ & 0.59 \\
\hline
\end{tabular}

Note: Data are presented as $n(\%)$, mean $\pm S D$, or median (interquartile range).

Abbreviations: ICS, inhaled corticosteroid; LABA, long-acting $\beta$-agonist; LAMA, long-acting muscarinic antagonist. 


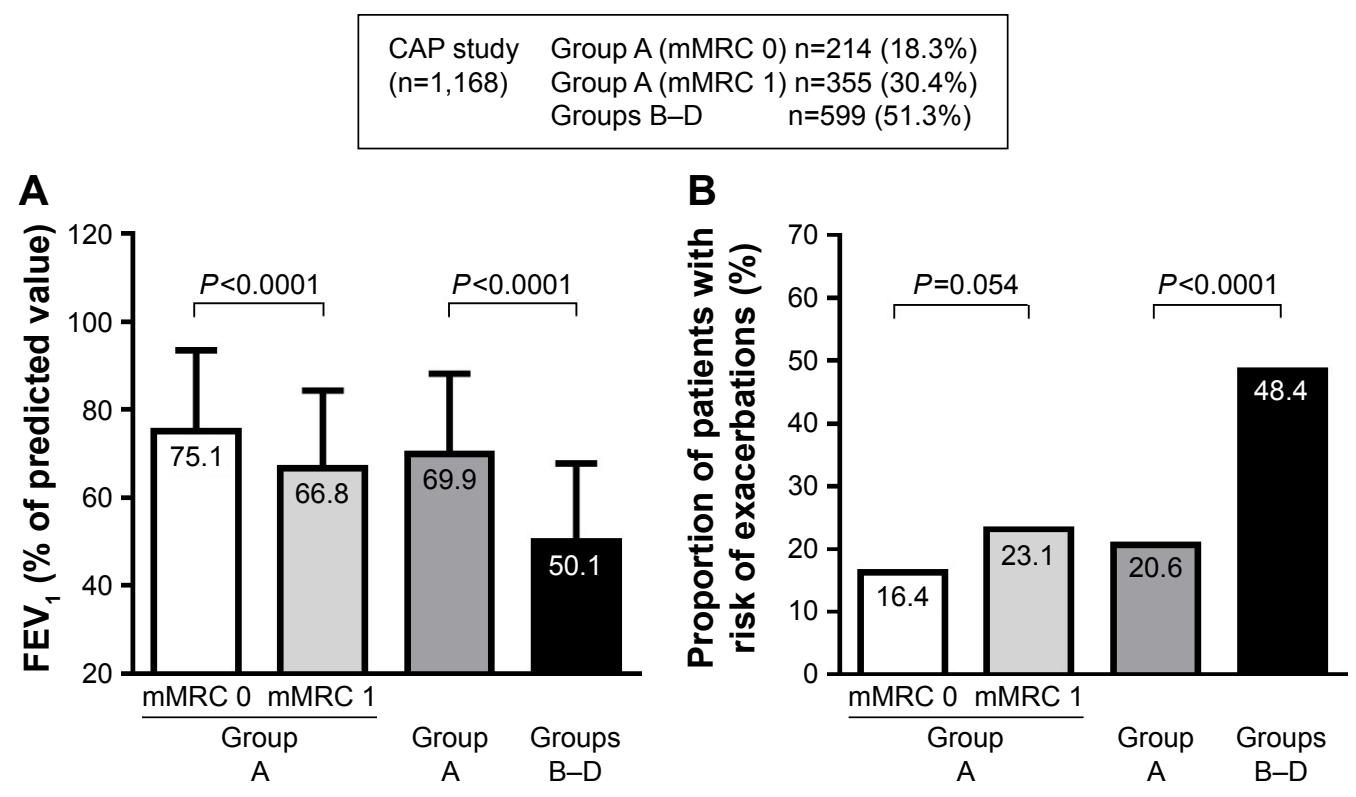

Figure 3 Differences in the airflow limitation and exacerbation risk in accordance with the categories of $\mathrm{mMRC}$ grade 0 in group $\mathrm{A}$, mMRC grade I in group $\mathrm{A}$, group $\mathrm{A}$, and groups B-D.

Notes: (A) Significant differences in \%FEV, were found. (B) Regarding the proportion of patients with exacerbations, a significant difference between group A and groups $B-D$ was found, and a difference between $m M R C$ grades 0 and $I$ in group $A$ was found.

Abbreviation: CAP, COPD Assessment in Practice.

of symptoms and history of exacerbations. The changes revealed the shift of patients with poor pulmonary function from the high-risk groups to the low-risk groups. In our Asian population, compared with the 2015 schema, the 2017 GOLD ABCD classification significantly shifts patients from groups $\mathrm{C}$ and $\mathrm{D}$ to groups $\mathrm{A}$ and $\mathrm{B}$, and notably, group $\mathrm{A}$ is the most widely distributed group, and it accounts for approximately half of the patients. In this study, patients with COPD were enrolled from three primary care facilities and 12 secondary care facilities in Japan. The distribution of the patient categories in the GOLD ABCD classification may be different in different populations. Nevertheless, this classification shift trend and the fact that group A was the most predominant group were also reported in the previous COPD cohorts. ${ }^{5,6}$ The usefulness of this new ABCD classification in 2017 GOLD remains to be evaluated, and it will be necessary to work on investigating the features of group A. The characteristics of group A are in line with previous studies in which group A was younger, had a higher proportion of current smokers, and had higher pulmonary function. ${ }^{5,6}$ The pharmacotherapy of group A was poorly documented in previous studies. ${ }^{5,6}$ In the current study, we demonstrated that the proportion of monotherapy of long-acting bronchodilators was larger in group A than that in groups B-D. Based on the above characteristics, group $\mathrm{A}$ has plenty of room for management improvements such as smoking cessation and combination therapy of long-acting bronchodilators.
Second, the prevalence of mMRC grade 1 patients was about two-thirds of group A and, compared with the mMRC 0 patients, mMRC 1 patients had a tendency to have a higher proportion of exacerbations and had a significantly lower pulmonary function. Regardless of the mMRC grade, there was not much difference in the physicians' pharmacotherapy selection in group A. To our best knowledge, this is the first study to examine the characteristics, by stratifying according to the mMRC scale (grade 0 or 1 ), of group A patients. Our findings concerning the severity of the spirometric airflow limitation in group A were compatible with those of a previous study. ${ }^{5}$ In our study, the GOLD 1 rate in the mMRC grade 1 and the GOLD 2-3 rate in the mMRC grade 0 in group A were $23 \%$ and $56 \%$, respectively. The mMRC scale was independently associated with $\mathrm{FEV}_{1}$, although the determinants of the mMRC scale were associated with multiple factors. ${ }^{14}$ Even patients with mild airflow limitation may show hyperinflation of the chest, which is associated with exertional dyspnea. ${ }^{15}$ Even in smokers with only mild spirometric abnormalities, gas exchange abnormalities, dyspnea, and exercise intolerance were apparent. ${ }^{16}$ Although it is important to evaluate the $\mathrm{FEV}_{1}$ in COPD patients, there is no need to put too much emphasis on $\mathrm{FEV}_{1}$.

The risk of exacerbation in mMRC grade 1 in group A was greater than in mMRC grade 0 , though the difference was not statistically significant $(P=0.054)$. Our study was a cross-sectional observational study, and patients were not 
evaluated for the long-term risk of exacerbation. However, in a recent prospective study, Natori et $\mathrm{al}^{30}$ demonstrated that evaluation of the mMRC scale for COPD exacerbation could be used to predict exacerbation, even though the risk of exacerbation in $\mathrm{mMRC}$ grade 1 patients was more increased than in $\mathrm{mMRC}$ grade 0 patients. Exertional dyspnea often causes COPD patients to unconsciously reduce their activities of daily living in order to reduce the intensity of their distress. ${ }^{17}$ Exertional dyspnea was also associated with physical inactivity and the risk of comorbidities. Assessment of dyspnea by the mMRC scale would be useful to stratify the risk of reduced physical activity in COPD. ${ }^{18}$ Moreover, the $\mathrm{mMRC}$ scale showed a clear relationship with the health status scores; even mMRC grade 1 was associated with the health status impairment. ${ }^{19}$ In our study, the prevalence of mMRC grade 1 patients was about two-thirds of group A. mMRC grade $\geq 2$ was associated with significantly shorter all-cause survival. ${ }^{20}$ Based on these findings, it is important to consider the development of an effective COPD management plan that prevents patients progressing from mMRC grade 0 or 1 to $\mathrm{mMRC}$ grade $>2$.

Importantly, despite the fact that there were changes in the exacerbation risk and airflow limitation between mMRC grades 0 and 1 in group A, there was not much difference in the physicians' pharmacotherapy selection. The 2017 GOLD report suggested that all group A patients should be offered a bronchodilator to reduce breathlessness and use of the bronchodilator should be continued if a symptomatic benefit is noted. ${ }^{4}$ Bronchodilators were effective in improving dyspnea in patients with COPD. ${ }^{21-23}$ Even in patients with less dyspnea (mMRC grade $<2$ ), indacaterol or tiotropium monotherapy significantly and clinically improved the transition dyspnea index score by the minimum clinically important difference ( $\geq 1$ point). ${ }^{24}$ According to a recent meta-analysis, LABA/ LAMA combination therapy improved the transition dyspnea index score more than LABA or LAMA monotherapy. ${ }^{25}$ Bronchodilators could improve the physical activity in patients with COPD, but the improvement was seen in the patients with better baseline lung volume. ${ }^{26}$

Bronchodilator intervention could provide benefits in the early stage of COPD. In our mMRC grade 1 patients in group $\mathrm{A}$, the proportions of monotherapy and LABA/ LAMA combination therapy were $57.2 \%$ and $38.3 \%$, respectively. For mMRC grade 1 patients in group A with persistent breathlessness on monotherapy of long-acting bronchodilators, there might be room to consider a combination therapy of long-acting bronchodilators. Further study in group A patients is needed to assess the efficacy of early intervention with pharmacotherapy.
This study had several limitations. First, because the study cohort is taken from primary and secondary health care, thus limited to subjects already diagnosed, the possibility of underdiagnosis of COPD could not be removed completely. Especially, group A includes patients with little or no dyspnea, which implies that many patients may not be diagnosed. This is a selection bias in our study. Second, the proportion of females in this study is very limited. Third, our study did not measure the CAT. Because the CAT covers a broad variety of symptoms, CAT and $\mathrm{mMRC}$ really explore different aspects. While previous studies found a significant association between the mMRC grade and the health status scores including CAT scores, ${ }^{19,27}$ various studies demonstrated that the GOLD ABCD classification produced by the mMRC or CAT score was not identical. ${ }^{28,29}$ Further studies are warranted to confirm the stratification by CAT in group A. Fourth, this study was a cross-sectional observational study, and patients were not followed up to evaluate long-term clinical outcomes such as exacerbation frequency and mortality. Finally, various therapies and comorbidities may have influenced the clinical characteristics. Further broader studies are required to assess the long-term clinical outcomes and the efficacy of various therapies and comorbidities.

\section{Conclusion}

Group A patients accounted for half of the patients, and they were younger, had higher pulmonary function, and had lower pharmacotherapy intensity compared with groups B-D. By stratifying according to the mMRC grade 0 or 1 in group A patients, there were differences in the exacerbation risk and airflow limitation. By stratifying according to the mMRC grade 0 or 1 in group A patients, there were differences in the exacerbation risk and airflow limitation. Further study in group A patients is needed to assess the long-term prognosis and the efficacy of early intervention with pharmacotherapy.

\section{Acknowledgment}

The authors thank Mr Brent Bell for reading the manuscript.

\section{Author contributions}

$\mathrm{KO}, \mathrm{TH}, \mathrm{KH}, \mathrm{SU}, \mathrm{RS}, \mathrm{YY}, \mathrm{KI}, \mathrm{MA}-\mathrm{N}, \mathrm{NE}$, and KM all made substantial contributions to the conception and design of the study, the acquisition, analysis, and interpretation of data. All authors contributed toward the drafting of the article and revising it critically for important intellectual content. All authors provided their final approval of the version to be published. The authors are accountable for the accuracy and integrity of this work. 


\section{Disclosure}

The authors report no conflicts of interest in this work.

\section{References}

1. National Institute for Health and Clinical Excellence (NICE). Chronic obstructive pulmonary disease in over-16s: diagnosis and management. NICE Guidelines [CG101]. London: NICE; 2010.

2. Fukuchi $Y$, Nishimura $M$, Ichinose $M$, et al. COPD in Japan: the Nippon COPD Epidemiology study. Respirology. 2004;9(4):458-465.

3. Buist AS, Mcburnie MA, Vollmer WM, et al. International variation in the prevalence of COPD (the BOLD Study): a population-based prevalence study. Lancet. 2007;370(9589):741-750.

4. From the Global Strategy for the Diagnosis, Management and Prevention of COPD. Global Initiative for Chronic Obstructive Lung Disease. 2017. Available from: http://goldcopd.org/gold-2017-global-strategydiagnosis-management-prevention-copd. Accessed July 30, 2018.

5. Cabrera López C, Casanova Macario C, Marín Trigo JM, et al. Comparison of the 2017 and 2015 global initiative for chronic obstructive lung disease reports. Impact on grouping and outcomes. Am J Respir Crit Care Med. 2018;197(4):463-469.

6. Sun L, Chen Y, Wu R, Lu M, Yao W. Changes in definition lead to changes in the clinical characteristics across COPD categories according to GOLD 2017: a national cross-sectional survey in China. Int J Chron Obstruct Pulmon Dis. 2017;12:3095-3102.

7. Matsunaga K, Hayata A, Akamatsu K, et al. Stratifying the risk of COPD exacerbation using the modified Medical Research Council scale a multicenter cross-sectional CAP study. Respir Investig. 2015;53(2): $82-85$.

8. Miller MR, Hankinson J, Brusasco V, et al. Standardisation of spirometry. Eur Respir J. 2005;26(2):319-338.

9. Sasaki HNM, Kida K. Reference values for spirogram and blood gas analysis in Japanese adults. JJRS. 2001;39(5):S1-S17.

10. Mahler DA, Wells CK. Evaluation of clinical methods for rating dyspnea. Chest. 1988;93(3):580-586.

11. Vestbo J, Hurd SS, Agustí AG, et al. Global strategy for the diagnosis, management, and prevention of chronic obstructive pulmonary disease: GOLD executive summary. Am J Respir Crit Care Med. 2013;187(4): 347-365.

12. Paggiaro PL, Dahle R, Bakran I, Frith L, Hollingworth K, Efthimiou J. Multicentre randomised placebo-controlled trial of inhaled fluticasone propionate in patients with chronic obstructive pulmonary disease. International COPD Study Group. Lancet. 1998;351(9105): 773-780.

13. Kanda Y. Investigation of the freely available easy-to-use software 'EZR' for medical statistics. Bone Marrow Transplant. 2013;48(3):452-458.

14. Perez T, Burgel PR, Paillasseur JL, et al. Modified medical research council scale vs baseline dyspnea Index to evaluate dyspnea in chronic obstructive pulmonary disease. Int J Chron Obstruct Pulmon Dis. 2015; 10:1663-1672.

15. Ofir D, Laveneziana P, Webb KA, Lam YM, O’Donnell DE. Mechanisms of dyspnea during cycle exercise in symptomatic patients with GOLD stage I chronic obstructive pulmonary disease. Am J Respir Crit Care Med. 2008;177(6):622-629.
16. Elbehairy AF, Ciavaglia CE, Webb KA, et al. Pulmonary gas exchange abnormalities in mild chronic obstructive pulmonary disease. implications for dyspnea and exercise intolerance. Am J Respir Crit Care Med. 2015;191(12):1384-1394.

17. Reardon JZ, Lareau SC, Zuwallack R. Functional status and quality of life in chronic obstructive pulmonary disease. Am J Med. 2006; 119(10 Suppl 1):32-37.

18. Hayata A, Minakata Y, Matsunaga K, Nakanishi M, Yamamoto N. Differences in physical activity according to mMRC grade in patients with COPD. Int J Chron Obstruct Pulmon Dis. 2016;11:2203-2208.

19. Jones PW, Adamek L, Nadeau G, Banik N. Comparisons of health status scores with MRC grades in COPD: implications for the GOLD 2011 classification. Eur Respir J. 2013;42(3):647-654.

20. Casanova C, Marin JM, Martinez-Gonzalez C, et al. Differential effect of modified medical research council dyspnea, COPD assessment test, and clinical COPD questionnaire for symptoms evaluation within the new GOLD staging and mortality in COPD. Chest. 2015;148(1):159-168.

21. Kinoshita M, Lee SH, Hang LW, et al. Efficacy and safety of indacaterol 150 and $300 \mu \mathrm{g}$ in chronic obstructive pulmonary disease patients from six Asian areas including Japan: a 12-week, placebo-controlled study. Respirology. 2012;17(2):379-389.

22. Koch A, Pizzichini E, Hamilton A, et al. Lung function efficacy and symptomatic benefit of olodaterol once daily delivered via Respimat ${ }^{\text {B }}$ versus placebo and formoterol twice daily in patients with GOLD 2-4 COPD: results from two replicate 48-week studies. Int J Chron Obstruct Pulmon Dis. 2014;9:697-714.

23. Vincken W, van Noord JA, Greefhorst AP, et al. Improved health outcomes in patients with COPD during 1 yr's treatment with tiotropium. Eur Respir J. 2002;19(2):209-216.

24. Mahler DA, Buhl R, Lawrence D, Mcbryan D. Efficacy and safety of indacaterol and tiotropium in COPD patients according to dyspnoea severity. Pulm Pharmacol Ther. 2013;26(3):348-355.

25. Rodrigo GJ, Price D, Anzueto A, et al. LABA/LAMA combinations versus LAMA monotherapy or LABA/ICS in COPD: a systematic review and meta-analysis. Int J Chron Obstruct Pulmon Dis. 2017;12: 907-922.

26. Minakata Y, Morishita Y, Ichikawa T, et al. Effects of pharmacologic treatment based on airflow limitation and breathlessness on daily physical activity in patients with chronic obstructive pulmonary disease. Int J Chron Obstruct Pulmon Dis. 2015;10:1275-1282.

27. Wilke S, Smid DE, Spruit MA, et al. The 2014 updated GOLD strategy: a comparison of the various scenarios. Chronic Obstr Pulm Dis. 2014; 1(2):212-220.

28. Kim S, Oh J, Kim YI, et al. Differences in classification of COPD group using COPD assessment test (CAT) or modified Medical Research Council (mMRC) dyspnea scores: a cross-sectional analyses. BMC Pulm Med. 2013;13:35.

29. Huang WC, Wu MF, Chen HC, Hsu JY; TOLD Group. Features of COPD patients by comparing CAT with mMRC: a retrospective, crosssectional study. NPJ Prim Care Respir Med. 2015;25:15063.

30. Natori H, Kawayama T, Suetomo M, et al. Evaluation of the modified medical research council dyspnea scale for predicting hospitalization and exacerbation in Japanese patients with chronic obstructive pulmonary disease. Intern Med. 2016;55(1):15-24.
International Journal of COPD

\section{Publish your work in this journal}

The International Journal of COPD is an international, peer-reviewed journal of therapeutics and pharmacology focusing on concise rapid reporting of clinical studies and reviews in COPD. Special focus is given to the pathophysiological processes underlying the disease, intervention programs, patient focused education, and self management protocols.

\section{Dovepress}

This journal is indexed on PubMed Central, MedLine and CAS. The manuscript management system is completely online and includes a very quick and fair peer-review system, which is all easy to use. Visit http://www.dovepress.com/testimonials.php to read real quotes from published authors. 